\title{
Commentary: When less is more: Is valve repair the optimal intervention for aortic insufficiency at time of ventricular assist device implantation?
}

\author{
Jason J. Han, MD, and Pavan Atluri, MD
}

\footnotetext{
From the Division of Cardiovascular Surgery, Department of Surgery, University of Pennsylvania, Philadelphia, $\mathrm{Pa}$.

Disclosures: Authors have nothing to disclose with regard to commercial support.

Received for publication Nov 11, 2018; accepted for publication Nov 12, 2018; available ahead of print Dec 28, 2018.

Address for reprints: Pavan Atluri, MD, Division of Cardiovascular Surgery, Hospital of the University of Pennsylvania, 3400 Spruce St, 6 Silverstein Pavilion, Philadelphia, PA (E-mail: Pavan.Atluri@uphs.upenn.edu). J Thorac Cardiovasc Surg 2019;157:e385-6 $0022-5223 / \$ 36.00$

Copyright (c) 2018 by The American Association for Thoracic Surgery https://doi.org/10.1016/j.jtcvs.2018.11.044
}

As the use of left ventricular assist devices (LVADs) continues to increase, especially for long-term, destination therapy, progressive aortic insufficiency (AI) is a major limitation to its durability. ${ }^{1}$ The etiology is believed to be multifactorial, driven by both the device-generated pressure gradient across the aortic valve (AV) as well as the subsequent structural changes that take place such as annular dilatation, mal-coaptation of AV leaflets, and eventual commissural fusion. ${ }^{2}$ Clinicians have proposed that allowing the $\mathrm{AV}$ to open intermittently as a potential option to mitigate the risk of developing AI; however, this is not always feasible nor proven. Worsening AI eventually results in significant recycling of device output and therefore decompensated heart failure (HF), which poses a challenge to the HF community because by this point their risk in undergoing conventional open-heart surgery may be significantly elevated. Although transcatheter approaches have been reported to treat the development of de novo AI, this area remains largely anecdotal and remains to be fully investigated for this off-label use. ${ }^{3}$

More than $30 \%$ of patients develop de novo, greater-thanmoderate AI by 2 years after LVAD implantation. ${ }^{4}$ Existing $\mathrm{AI}$, as in the case presented by Barac and colleagues ${ }^{5}$ in this issue of the Journal, must be addressed at the time of implantation. ${ }^{6}$ However, finding the solution has been challenging because previous studies have suggested an increased mortality in patients who undergo concomitant AV repair, replacement or closure, as the added operative insult is likely poorly tolerated in this patient population. ${ }^{7}$ Particularly, methods of AV closure such as Park's stitch may increase the risk of sudden death in the setting of device failure or thrombosis. ${ }^{8}$ Moreover, AV replacement may be associated with bioprosthetic valve thrombosis and fusion.

In this setting, the authors' report of successful AV ring annuloplasty proposes a meaningful alternative for patients with existing AI or at high risk of developing de

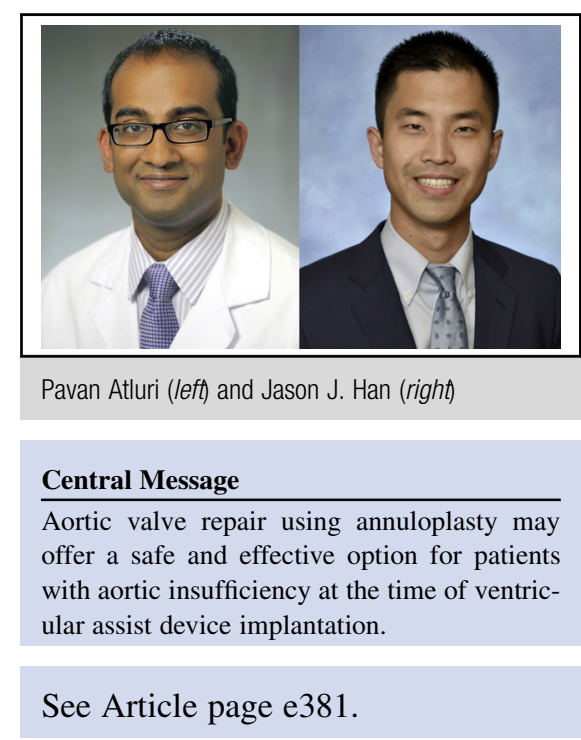

novo AI at the time of implantation. The compelling benefits include the ability to conserve the integrity of native AV leaflets, which may further protect against VADrelated AI. Annuloplasty appears to be successful in the short term, as the authors report minimal AI at a 2-month follow-up; its mid- to long-term durability as well as effects of AV opening status remain to be explored. Furthermore, patient selection will be critical to the success of annuloplasty, which may be less effective in addressing AI that is secondary to causes other than annular dilatation such as leaflet degeneration. One foreseeable limitation is that because the pathologic changes associated with de novo AI appear to be related to commissural fusion, it is difficult to know whether this corrective approach will be durable long term. Lastly, based on this report, it is difficult to ascertain just how much crossclamp or bypass time this approach will ultimately save compared with a Park stitch or AV replacement. In this patient cohort, crossclamp time is not trivial for an often-associated dysfunctional right ventricle.

Overall, the authors ought to be congratulated for their successful demonstration of concomitant AV annuloplasty at the time of LVAD implantation with excellent shortterm outcome. As the HF and MCS community seeks to address the feasibility of long-term VAD support to potentially rival the durability of heart transplantation in certain patients, mitigating the risk of $\mathrm{AI}$ is crucial. By combining 
their expertise in mechanical circulatory support and valvular surgery, they have raised a compelling, innovative alternative to the existing surgical repertoire in the literature for this rapidly growing population.

\section{References}

1. Cowger J, Rao V, Massey T, Sun B, May-Newman K, Jorde U, et al. Comprehensive review and suggested strategies for the detection and management of aortic insufficiency in patients with a continuous-flow left ventricular assist device. J Heart Lung Transplant. 2015;34:149-57.

2. Connelly JH, Abrams J, Klima T, Vaughn WK, Frazier OH. Acquired commissural fusion of aortic valves in patients with left ventricular assist devices. J Heart Lung Transplant. 2003;22:1291-5.

3. Rene AG, Desai N, Wald J, Rame JE, Frogel JK, Anwaruddin S. Transfemoral transcatheter aortic valve replacement with a self-expanding valve for severe aortic regurgitation in a patient with left ventricular assist device. J Card Surg. 2017:32:741-5.

4. Cowger J, Pagani FD, Haft JW, Romano MA, Aaronson KD, Kolias TJ. The development of aortic insufficiency in left ventricular assist device-supported patients. Circ Heart Fail. 2010;3:668-74.

5. Barac YD, Castleberry AW, Patel CB, McCartney SL, Schroder JN. Aortic valve ring annuloplasty is an option in left ventricular assist device patients. J Thorac Cardiovasc Surg. 2019;157:e381-3.

6. Schroder JN, Milano CA. Is it time to get more aggressive with aortic valve insufficiency during LVAD implantation? JACC Heart Fail. 2018;6:961-3.

7. Robertson JO, Naftel DC, Myers SL, Prasad S, Mertz GD, Itoh A, et al. Concomitant aortic valve procedures in patients undergoing implantation of continuousflow left ventricular assist devices: an INTERMACS database analysis. J Heart Lung Transplant. 2015;34:797-805.

8. Park SJ, Liao KK, Segurola R, Madhu KP, Miller LW. Management of aortic insufficiency in patients with left ventricular assist devices: a simple coaptation stitch method (Park's stitch). J Thorac Cardiovasc Surg. 2004;127:264-6. 